\title{
FrancoAmerican Combined Technique of Thoracoscopic Pulmonary Lobectomy in Infants
}

Andrew F. Zigman, MD, CM

Division of Pediatric Surgery, Northwest Permanente Physicians and Surgeons, Oregon Health and Sciences University, Portland, Oregon.

E-mail: andrew.f.zigman@kp.org

Ryan G. Spurrier, MD

Division of Pediatric Surgery, Oregon Health and Sciences University, Portland, Oregon.

Presented at the International Pediatric Endosurgery Group (IPEG) Annual Meeting, March 22, 2019, Santiago, Chile.

(c) Mary Ann Liebert, Inc. DOI: 10.1089/vor.2019.0582
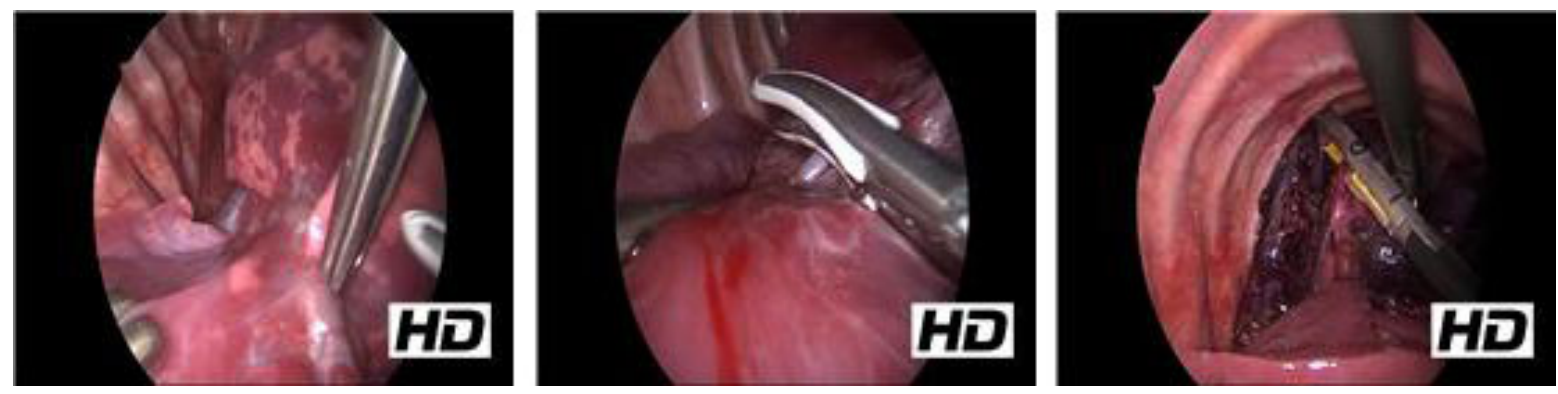

\section{Abstract}

Introduction: This 5-minute-long video demonstrates a combined technique of thoracoscopic right lower pulmonary lobectomy.

Materials and Methods: The operation combines the techniques of IPEG colleagues Arnaud Bonnard from Paris, France, ${ }^{1}$ and Steven Rothenberg from Denver, United States of America. ${ }^{2}$ The video demonstrates the steps of the procedure. The French contribution is the port and camera position, where the surgeon stands at the foot of the patient looking directly up the fissure. The American contribution is the use of a sealing device for the vessels and a stapler for the bronchus.

Results and Conclusions: This combined technique utilizes a sealing device to control all vessels, and a stapler for the bronchus. Notably, with the telescope looking directly up the fissure, it allows for a more intuitive orientation to the pulmonary hilar structures. This has allowed for easier instruction of laparoscopic pulmonary lobectomy to trainees.

No competing financial interests exist.

Runtime of video: 5 mins 9 secs

Presented at the International Pediatric Endosurgery Group (IPEG) Annual Meeting, March 22, 2019, Santiago, Chile.

Keywords: thoracoscopic, pulmonary, lobectomy, infant, pediatric; FACT

\section{Cite this video}

Andrew F. Zigman, Ryan G. Spurrier, FrancoAmerican Combined Technique of Thoracoscopic Pulmonary Lobectomy in Infants, Videoscopy. 2019, DOI: 10.1089/vor.2019.0582. 


\section{References}

1. Boubnova J, Peycelon M, Garbi O, David M, Bonnard A, De Lagausie P. Thoracoscopy in the management of congenital lung diseases in infancy. Surg Endosc 2011;25:593-596.

2. Rothenberg $\mathrm{S}$. Thoracoscopic lobectomy in infants and children utilizing a $5 \mathrm{~mm}$ stapling device. J Laparoendosc Adv Surg Tech A 2016;26:1036-1038.

Original Publication Date: 2019 